\title{
Diamond: Molten under Pressure
}

\section{Citation}

Silvera, Isaac F. 2010. Diamond: Molten under pressure. Nature Physics 6(1): 9-10.

\section{Published Version}

doi:10.1038/nphys 1491

\section{Permanent link}

http://nrs.harvard.edu/urn-3:HUL.InstRepos:9121282

\section{Terms of Use}

This article was downloaded from Harvard University's DASH repository, and is made available under the terms and conditions applicable to Open Access Policy Articles, as set forth at http:// nrs.harvard.edu/urn-3:HUL.InstRepos:dash.current.terms-of-use\#OAP

\section{Share Your Story}

The Harvard community has made this article openly available.

Please share how this access benefits you. Submit a story.

\section{Accessibility}




\section{Melting of Diamond at Colossal Pressures}

Diamond, made of pure carbon, the atom at the heart of life, is one of the most remarkable materials occurring naturally in nature. Diamond is the hardest material known to man. Diamond is transparent in visible light. Diamond is a metastable form of carbon. Atoms in a solid organize themselves to be in the lowest energy state; in a metastable substance atoms are organized in a higher energy state, prevented from transforming to the lower energy state by an energy barrier. Thus, the lowest energy state of carbon is graphite with atoms forming a hexagonal lattice, which if subjected to a large pressure and high temperature transforms to diamond with atoms on a cubic lattice. When cooled and the pressure is released the carbon atoms remain in the metastable diamond structure. This process is carried out in the depths of the earth as nature provides us with diamonds that have "boiled" up to the crust; man has learned how to make diamond from graphite, synthetically. Most solids, when heated, melt into a liquid, and then vaporize into a gas. If a diamond is sufficiently heated it does not melt, but transforms to graphite. It is not recommended that one experimentally put this statement to the test with cubic carbon mounted on a ring. To actually melt diamond it must be subjected to large pressures and heated. The melting line of diamond is the locus of pressure/temperature points where the solid transforms to the liquid. On page xxx of this issue, Eggert et al (ref) have determined the melting line of diamond to the extraordinary pressure of 11 megabars, using a high energy pulsed laser to shock compress and heat diamond into the liquid phase.

Melting lines can be studied by static pressures and temperatures or pulsed pressures and heating. In the static method pressures of order 2-4 megabar can be achieved by compressing samples between diamond anvils. Diamond cells can be heated to several hundred degrees, which is insufficient to effectively probe the melt line of diamond. Pressurized samples can be heated to several thousand degrees by absorbing the energy from focused lasers, but because diamond is transparent little of the laser energy is absorbed and the diamond sample barely heats. Shock waves can achieve both high pressures and temperatures. In the traditional method a massive high velocity projectile impacts a sample, launching a propagating shock wave. Behind the wave the sample is compressed to a steady high pressure and temperature and the action takes place in a few nanoseconds; in the best of cases one measures the velocity of the shock front and the particle velocity. The object is to determine the pressure, $P$, density $\rho$, and the temperature, T. Excluding the temperature, these quantities and the internal energy, E, can be related from conservation laws yielding three equations, the Rankine-Hugoniot equations. If possible, the challenging determination of the temperature is measured independently. In general for each shock a single $\mathrm{P}, \mathrm{T}$ point is determined, and after the shock impact, little is left of the experimental stage. Recently the high pressure phases of diamond have been studied by Knudson, Desjarlais, and Dolan (ref) using this method.

With the development of high power pulsed lasers a new method of creating shocks has been under development in the last decade or two. The powerful laser energy incident on the sample ionizes it at the surface and the energy is efficiently absorbed. The ablating materials at the surface transfer their momentum to the sample launching a shock wave. In the experiment of Eggert et al, the OMEGA laser at the University of Rochester was used, with $1 \mathrm{~ns}$ pulses, up to $3 \mathrm{~kJ}$ ( $\sim 3 \times 10^{12}$ Watts) generating pressures up 
to 40 megabar and temperatures up to $100,000 \mathrm{~K}$. Because the pulse is limited in time, the shock is not steady or supported, and decays in time. The leading edge achieves the extreme conditions, but because of the decay a single shock samples a continuum of $\mathrm{P}, \mathrm{V}$, $\mathrm{T}$ states. The temperature of the shocked region was measured by fitting the irradiance or blackbody radiation, measured with an optical pyrometer, to a Planck blackbody curve with appropriate consideration for the emissivity. At the earliest time in the pulse the temperature and pressure peak deep into the liquid zone, but as P and T decay, instead of continuing down to ambient, the curve plateaus. This plateau region is interpreted as the melt line with energy being released in the heat of transformation.

The melting curve has a small negative curvature (a peak, with $\mathrm{T}$ decreasing with increasing pressure beyond the peak) in agreement with recent theory (ref). Reflectivity of the diamond was also measured. This rises sharply in the melt and has been interpreted as liquid carbon being a metallic fluid. These measurements also allow for the determination of the specific heat of the sample. A peak in the region of melting is speculated to arise from partial bonding in the fluid metal, developing to an atomic fluid at higher temperatures.

These measurements are a precursor to a new regime of high pressure-high temperature physics. With the much higher power NIF (National Ignition Facility) laser coming on line we can expect much higher pressures than the ones achieved on diamond in this research. New and surprising physics may emerge as atoms are compressed to the core electron levels. 